\title{
Retrospective analyses versus RCTs: comparing like with like?
}

\author{
Ralf Baron' \\ Lieven Nils Kennes ${ }^{2}$ \\ Christian Elling ${ }^{3}$ \\ 'Division of Neurological Pain \\ Research and Therapy, Department \\ of Neurology, University Hospital \\ of Schleswig-Holstein, Kiel Campus, \\ Kiel, ${ }^{2}$ Department of Economics and \\ Business Administration, University of \\ Applied Sciences Stralsund, Stralsund, \\ ${ }^{3}$ Grünenthal $\mathrm{GmbH}$, Medical Affairs \\ Europe and North America, Aachen, \\ Germany
}

This article was published in the following Dove Press journal: Journal of Pain Research

31 March 2017

Number of times this article has been viewed

\section{Dear editor}

In their recent retrospective analysis assessing oxycodone/naloxone (OXN) vs. tapentadol (TAP) treatment for chronic low-back pain with a neuropathic component, Ueberall and Mueller-Schwefe ${ }^{1}$ compare their results to the findings of an earlier phase $3 \mathrm{~b} / 4$ study. ${ }^{2}$ In our opinion, a proper comparison to the prospective, randomized, controlled, open-label study by Baron and colleagues is scientifically not appropriate. Although Ueberall and Mueller-Schwefe use the terms "prospective," "randomly," and "blinded" and refer to the PROBE design (prospective, randomized, open-label, blinded endpoint), ${ }^{3}$ their database study is retrospective, nonrandomized, and nonblinded with the treatment choice left to the discretion of the physicians. In this context, the use of the term "intention-to-treat (ITT) population" is inappropriate because ITT is unambiguously defined as including all randomized subjects and thus inseparable from true randomization $\left(\mathrm{ICH}\right.$ E9) ${ }^{4}$.

Additionally a difference exists between both studies regarding analgesic pretreatment. Nearly $70 \%$ of patients in the Ueberall study were pretreated with World Health Organization (WHO) Step II analgesics, whereas patients in the Baron study were not currently taking opioids. This difference very likely has a number of implications regarding, for instance, constipation at baseline and the overall efficacy and safety results. In fact, approximately a quarter of the patients in the Ueberall study already used laxatives at baseline, which points to the correctness of this assumption. Furthermore, no information concerning concomitant analgesics and co-analgesics use during the assessment is given in the Ueberall publication. Thus, it is conceivable that for many patients an add-on treatment of OXN or TAP was assessed in contrast to Baron, where the two compounds were compared without these confounding factors.

Additionally we would like to highlight some misleading/incorrect statements in the Ueberall publication:

- TAP is described “... as a mild $\mu$-opioid receptor agonist (with a relative potency of $2 \%$ vs. morphine)..." and later again "...the $\mu$-opioid receptor activity of TAP is approximately only $2 \%$ versus. morphine...". This percentage is related to TAPs binding affinity for the $\mu$-opioid receptor and does neither indicate relative potency nor receptor activity. In the clinic TAP has demonstrated potent strong analgesic efficacy consistent with its dual mechanism of action, that is, $\mu$-opioid receptor agonism and noradrenaline (NA) reuptake inhibition.
Correspondence: Christian Elling Grünenthal $\mathrm{GmbH}$, Medical Affairs Europe and North America, Zieglerstr. 6, 52078 Aachen, Germany Email Christian.Elling@grunenthal.com 
- According to Ueberall and Mueller-Schwefe, patients in the titration period of the Baron study "had to reach a definite dose level." The respective study publication, however, clearly states that the titration target was based on pain relief (numerical rating scale $[\mathrm{NRS}]-3 \leq 4$ or $\leq 5$ ) and tolerability. ${ }^{2}$ A dose target was not required at any time.

- The conclusion of insignificant changes of laxative use for both treatments is incorrect. Given a baseline/ end-of-treatment scenario, paired nominal data are present, where assessments of the same individual are stochastically dependent. The correct testing procedure for this scenario is not mentioned in the publication. Conducting the appropriate McNemar's test with Edward's continuity correction for paired nominal data to analyze the discordant pairs for both treatments demonstrates a significant change (worsening) in the use of laxatives from baseline to the end of treatment for OXN ( $p=0.004)$ and a clear trend of improvement for TAP $(p=0.073)$.

We agree with the authors that real live data are a valuable addition to the knowledge gained from clinical trials; however, we disagree on comparing data assessed in a randomized controlled trial with retrospective database analyses, which exhibit a high number of confounding factors.

\section{Disclosure}

Ralf Baron was the principal investigator of the study used for comparison. He received grants/research supports from Pfizer, Genzyme, Grünenthal, and Mundipharma. He is a member of EU Project No 633491 DOLORisk, German
Federal Ministry of Education and Research (BMBF): ERANET NEURON, IM-PAIN Project, German Research Network on Neuropathic Pain, NoPain system biology, German Research Foundation (DFG). He received speaking fees from Pfizer, Genzyme, Grünenthal, Mundipharma, Sanofi Pasteur, Medtronic, Eisai, Lilly, Boehringer Ingelheim, Astellas, Desitin, Teva Pharma, Bayer-Schering, MSD, and Seqirus. He was also a consultant for Pfizer, Genzyme, Grünenthal, Mundipharma, Allergan, Sanofi Pasteur, Medtronic, Eisai, Lilly, Boehringer Ingelheim, Astellas, Novartis, BristolMyers-Squibb, Biogenidec, AstraZeneca, Merck, AbbVie, Daiichi Sankyo, Glenmark Pharmaceuticals, Seqirus, Teva Pharma, Genentech, and Galapagos. Lieven Nils Kennes was the statistician of the study used for comparison. Christian Elling is an employee of the study sponsor, Grünenthal $\mathrm{GmbH}$. The authors report no other conflicts of interest in this communication.

\section{References}

1. Ueberall MA, Mueller-Schwefe GHH. Efficacy and tolerability balance of oxycodone/naloxone and tapentadol in chronic low back pain with a neuropathic component: a blinded end point analysis of randomly selected routine data from 12-week prospective open-label observations. J Pain Res. 2016;9:1001-1020.

2. Baron R, Likar R, Martin-Mola E, et al. Effectiveness of tapentadol prolonged release (PR) compared with oxycodone/naloxone $\mathrm{PR}$ for the management of severe chronic low back pain with a neuropathic component: a randomized, controlled, open-label, phase $3 \mathrm{~b} / 4$ study. Pain Pract. 2016;16:580-599.

3. Hansson L, Hedner T, Dahlöf B. Prospective randomized open blinded end-point (PROBE) study. A novel design for intervention trials. Blood Press. 1992;1(2):113-119.

4. International Conference on Harmonisation of Technical Requirements for Registration of Pharmaceuticals for Human Use. ICH Harmonised Tripartite Guideline. Statistical Principles for Clinical Trials E9. 1998. Available from: http://www.ich.org/fileadmin/Public_Web_Site/ICH_ Products/Guidelines/Efficacy/E9/Step4/E9_Guideline.pdf. Accessed January 16, 2017 


\section{Authors' reply}

Michael A Ueberall'

\section{Gerhard H H Mueller-Schwefe ${ }^{2}$}

'Institute of Neurological Sciences, Nuernberg, ${ }^{2}$ Interdisciplinary Center for Pain and Palliative Care Medicine, Goeppingen, Germany

Correspondence: Michael A Ueberall

Institute of Neurological Sciences, Nordostpark 5I, 904II Nuernberg, Germany

$\mathrm{Tel}+4991 / 21773760$

Fax +49 9II 21773761

Email michael.ueberall@ifnap.de

\section{Dear editor}

Thank you for the opportunity to reply to the letter of Baron et al. and to discuss their objections concerning our analysis of data from the German Pain Registry.

As we have described in our publication, ${ }^{1}$ the data for our analysis were not prospectively gathered during a doubleblind randomized controlled trial (RCT), but retrospectively taken from the German Pain Registry. This registry is a large database that provides detailed data (based on validated patient questionnaires and physician-recorded information on treatments, and so on) on the routine treatment of pain patients for health care research purposes, but its original intention is to provide patients and physicians a platform to optimize individual treatments during daily life care. Patients with low-back pain (LBP) with a neuropathic component in whom a new treatment with either oxycodone/naloxone (OXN) or tapentadol (TAP) was initiated within a specific period were identified by predefined inclusion and exclusion criteria (as described in our paper). From those patients who fulfilled the enrollment criteria for analysis, we then took a random sample to guarantee an unbiased patient selection for analysis and evaluated the effects of both treatments over a 12-week observation period in a blinded fashion.

Baron and colleagues argue that this specific type of analysis is different to those chosen by themselves for their prospectively randomized open-label study on OXN vs. TAP, ${ }^{2}$ and this was exactly our intention! We were not interested to replicate further virtual RCT data (where physicians and patients were constrained to follow specific procedures defined in a study protocol) but to get insight into the real-life effects of both treatments, when physicians are not only allowed to choose the ideal treatment for their patients (based on their specific individual pain problems, pretreatments, comorbidities, and so on), but also to tailor dose titration and maintenance therapy according to individual patient needs.
From a methodological point of view, this approach results in a positive selection (for both drugs evaluated!); however, from a practitioner's point of view this procedure reflects daily life practice, because physicians care for the individual needs of individual patients (not for group-related average scores or specific study requirements) and usually try to optimize the selected treatments according to the specific requirements of specific individuals.

These different approaches (either the ability to tailor an individually selected treatment according to the individual patient needs without any external influences and only for the purpose to improve the patient situation vs. the necessity to introduce a randomly selected treatment according to the recommendations given in a specified study protocol for the purpose of scientific research) result in significant differences with respect to distinct outcome parameters (especially the attrition rates of patients on treatment) and endpoint analyses - as we have discussed extensively in our paper.

Baron and colleagues noted that in our analysis OXN and TAP were given as an add-on-treatment in contrast to their study, where all analgesic treatments had to be washed out prior to study entry to finally qualify for enrollment. This is correct, but this is also one of our major concerns regarding the transferability of the results of the Baron study into real life. Under the conditions of routine care, no physician would force a patient to stop all prior analgesics just to start a new treatment. This approach - frequently chosen in RCTs not only to artificially worsen the pain intensity and other parameters at baseline, but also as a justification for specific recommendations to reach a definite level of pain relief within a short time (i.e., 3 weeks in the Baron study) - is contradictory with any daily-life approaches and (even if usually accepted by ethic committees and review boards) unethical under routine care conditions.

Dose titration (especially in case of potent opioid analgesics such as OXN) is a rather complex process that usually lasts weeks or even months and must be tailored to the individual patient needs and the effects and side effects reported by the patient. The specification to reach a definite degree of pain relief until the end of the 3-week titration period (to qualify study patients for the transfer into the maintenance phase of the Baron study) had a significant impact on the titration behavior and results in the largest dropout rate ever reported for OXN in an open-label study (51.6\% within 3 weeks, $62.5 \%$ for the whole study). This results indirectly in a positive discrimination of one comparator (TAP) vs. the other (OXN), simply because of the fact that TAP (as a week opioid receptor agonist) shares only few of the typical side effects of a potent opioid analgesic 
and can, therefore, be rapidly uptitrated without relevant side effects. In contrast to that, the forced titration of a potent opioid like OXN is usually followed by side effects and a consecutively higher rate of premature treatment discontinuations (as shown by the extraordinarily high discontinuation rates). In daily life, this is a clear advantage for TAP and probably one of the reasons why this drug is so frequently used by non-pain specialists and as a first-line alternative to nonsteroidal antiinflammatory drugs or other nonopioid analgesics, but in a study specifically designed to compare the analgesic efficacy of two drugs, this critical confounding factor executed a significant impact on the primary endpoint analysis (through the statistical techniques used to impute those data missing not at random) and should have been avoided to grant both comparators equal study conditions.

We thank the authors of the letter for their comments on the differential use of laxatives with both components evaluated in our analysis, and agree that there were statistically significant differences for that parameter between OXN and TAP.

Finally, we agree that the comparisons made by us between our analysis vs. those published by Baron and colleagues were obviously not comparisons of like with like, but more comparisons between the two sides of the same coin. Both approaches address different aspects of a treatment with OXN vs. TAP. Both approaches have several advantages and vice versa suffer several disadvantages and, therefore, none of them gives the one and only answer to the question how LBP patients with a neuropathic component should be treated. However, the data of both studies complement each other and by that way also enhance the knowledge and the ability of physicians to optimize the treatment of these patients under real-life conditions.

\section{Disclosure}

MAU and GHHMS are physicians and independent of any significant/relevant financial or other relationship to the sponsor, except for minor reimbursements for occasional lecture or consulting fees. Both are honorary members of the management boards of the German Pain Association and the German Pain League. The German Pain Registry is hosted by an independent contract research organization by order of the German Pain Association and under control of the Institute of Neurological Sciences and collects standardized data from daily routine medical care since January 2000. During the last 2 years, MAU received financial support and/ or expenses in the form of research money, consultancy fees, and/or remunerations for lecture activities from Almirall, Archimedes, Grünenthal, Kyowa Kirin, Menarini, MSD, Mucos, Mundipharma, Pfizer, PharmAllergan, Shionoghi, and TEVA. During the last 2 years, GHHMS received financial support and/or expenses in the form of research money, consultancy fees, and/or remunerations for lecture activities from Allergan, Almirall, Grünenthal, Kyowa Kirin, Mundipharma, Pfizer, PharmAllergan, Shionoghi, and TEVA. The authors report no other conflicts of interest in this communication.

\section{References}

1. Ueberall MA, Mueller-Schwefe GHH. Efficacy and tolerability balance of oxycodone/naloxone and tapentadol in chronic low back pain with a neuropathic component: a blinded end point analysis of randomly selected routine data from 12-week prospective open-label observations. J Pain Res. 2016;9:1001-1020.

2. Baron R, Likar R, Martin-Mola E, et al. Effectiveness of tapentadol prolonged release (PR) compared with oxycodone/naloxone PR for the management of severe chronic low back pain with a neuropathic component: a randomized, controlled, open-label, phase 3b/4 study. Pain Pract. 2016;16(5):580-599.

Dove Medical Press encourages responsible, free and frank academic debate. The content of the Journal of Pain Research 'letters to the editor' section does not necessarily represent the views of Dove Medical Press, its officers, agents, employees, related entities or the Journal of Pain Research editors. While all reasonable steps have been taken to confirm the content of each letter, Dove Medical Press accepts no liability in respect of the content of any letter, nor is it responsible for the content and accuracy of any letter to the editor

\section{Publish your work in this journal}

The Journal of Pain Research is an international, peer reviewed, open access, online journal that welcomes laboratory and clinical findings in the fields of pain research and the prevention and management of pain. Original research, reviews, symposium reports, hypothesis formation and commentaries are all considered for publication.
The manuscript management system is completely online and includes a very quick and fair peer-review system, which is all easy to use. Visit http://www.dovepress.com/testimonials.php to read real quotes from published authors. 